\title{
Physiological Maturation of Photoreceptors Depends on the Voltage-Gated Sodium Channel $\mathrm{Na}_{\mathrm{V}} 1.6($ Scn8a)
}

\author{
Patrice D. Côté, ${ }^{1}$ Yves De Repentigny, ${ }^{1}$ Stuart G. Coupland, ${ }^{2}$ Yannick Schwab, ${ }^{3}$ Michel J. Roux,${ }^{3}$ S. Rock Levinson, ${ }^{4}$ and \\ Rashmi Kothary ${ }^{1,5}$ \\ ${ }^{1}$ Molecular Medicine Program, Ottawa Health Research Institute, and University of Ottawa Center for Neuromuscular Disease, Ottawa, Ontario, Canada \\ K1H 8L6, ${ }^{2}$ Vision Program, Ottawa Health Research Institute, and University of Ottawa Eye Institute, Ottawa, Ontario, Canada K1H 8L6, ${ }^{3}$ Laboratoire de \\ Physiopathologie Moléculaire et Cellulaire de la Rétine, Institut National de la Santé et de la Recherche Médicale U592, Institut de Génétique et de Biologie \\ Cellulaire et Moléculaire, 67404 Illkirch Cedex, France, ${ }^{4}$ Physiology and Biophysics, University of Colorado Health Sciences Center, Denver, Colorado 80262, \\ and ${ }^{5}$ Departments of Medicine and Cellular and Molecular Medicine, University of Ottawa, Ottawa, Ontario, Canada K1H 8M5
}

Voltage-gated sodium channels (VGSCs) ensure the saltatory propagation of action potentials along axons by acting as signal amplifiers at the nodes of Ranvier. In the retina, activity mediated by VGSCs is important for the refinement of the retinotectal map. Here, we conducted a full-field electroretinogram (ERG) study on mice null for the sodium channel $\mathrm{Na}_{\mathrm{V}}$ 1.6. Interestingly, the light-activated hyperpolarization of photoreceptor cells (the a-wave) and the major "downstream" components of the ERG, the b-wave and the oscillatory potentials, are markedly reduced and delayed in these mice. The functional deficit was not associated with any morphological abnormality. We demonstrate that $S c n 8 a$ is expressed in the ganglion and inner nuclear layers and at low levels in the outer nuclear layer beginning shortly before the observed ERG deficit. Together, our data reveal a previously unappreciated role for VGSCs in the physiological maturation of photoreceptors.

Key words: voltage-gated sodium channel; $\mathrm{Na}_{\mathrm{V}} 1.6 ;$ Scn8a; retina; photoreceptors; electroretinogram; development

\section{Introduction}

By allowing sodium to enter excitable cells such as neurons and muscle in response to increases in membrane potential, voltagegated sodium channels (VGSCs) are essential to the generation and propagation of action potentials. The $\mathrm{Na}_{\mathrm{V}} 1.6$ channel, encoded by the Scn8a gene (Catterall, 2000; Goldin et al., 2000), is one of the most abundant VGSCs in the brain. It is the primary sodium channel expressed at the nodes of Ranvier in the CNS and peripheral nervous system (Caldwell et al., 2000), thus highlighting the importance of this particular VGSC isoform in saltatory conduction. $\mathrm{Na}_{\mathrm{V}} 1.6$ is also present in presynaptic and postsynaptic membranes of the neocortex and cerebellum (Caldwell et al., 2000), suggesting that it may also play an important role in modulating synaptic plasticity. In the adult retina, major sites of $\mathrm{Na}_{\mathrm{V}} 1.6$ expression include the ganglion cell and inner nuclear layers (Fjell et al., 1997; Krzemien et al., 2000). In the optic nerve, $\mathrm{Na}_{\mathrm{V}} 1.6$ is concentrated specifically at the nodes of Ranvier of myelinated axons and is absent from the unmyelinated axons (Boiko et al., 2001).

Several strains of mice harbor mutations in Scn8a (Meisler et

Received Nov. 16, 2004; revised April 8, 2005; accepted April 14, 2005.

This work was supported by the Muscular Dystrophy Association and the Human Frontier Science Program. P.D.C. is a fellow of the Canadian Institutes of Health Research. We are grateful to D. Petrin for technical assistance. We also thank V. Wallace for use of equipment and reagents and for helpful advice during the course of this work (others who have contributed reagents are acknowledged in Materials and Methods).

Correspondence should be addressed to Rashmi Kothary, Ottawa Health Research Institute, 501 Smyth Road, Ottawa, Ontario, Canada K1H 8L6. E-mail: rkothary@ohri.ca.

DOI:10.1523/JNEUROSCI.4692-04.2005

Copyright $\odot 2005$ Society for Neuroscience $\quad$ 0270-6474/05/255046-05\$15.00/0 al., 2001). In the original motor endplate disease (med) mouse $\left(S c n 8 a^{\text {med }}\right)$ described previously by Duchen (1970), a null mutation in Scn8a results in reduced neuromuscular transmission leading to paralysis and lethality approximately at the time of weaning (Burgess et al., 1995). Nerve conduction velocity is reduced and the refractory period is prolonged in these animals (Angaut-Petit et al., 1982). Additionally, degenerating muscle $(d m u)\left(S c n 8 a^{d m u}\right)$, a recently identified sporadic mutant allelic to $S c n 8 a^{\text {med }}$, displays cardiac and skeletal muscle degeneration (De Repentigny et al., 2001).

Here, we demonstrate that mice with null mutations in Scn8a display profound anomalies in a Ganzfeld flash electroretinogram (ERG), in both the a- and b-waves. We did not, however, detect abnormalities in retinal histology, ultrastructure, cellular contribution, or vasculature. Our demonstration that Scn8a transcript is expressed in the nuclear layers shortly before the elongation of the photoreceptor outer segments suggests that this channel directly influences the physiological maturation of photoreceptors.

\section{Materials and Methods}

Animals. The degenerating muscle allele arose spontaneously in our colony of $(\mathrm{C} 57 \mathrm{BL} / 6 \times \mathrm{C} 3 \mathrm{H}) \mathrm{F}_{1}$ hybrid mice and was mapped to the motor endplate disease locus (De Repentigny et al., 2001). To eliminate the possibility of interference from the $r d 1$ (retinal degeneration 1) locus on the $\mathrm{C} 3 \mathrm{H}$ genetic background, the mice were bred for three to four generations onto the DBA/2J or C57BL/6J backgrounds. We also obtained med mice from The Jackson Laboratory $\left(\mathrm{C} 3 \mathrm{HeB} / \mathrm{Fe}-\mathrm{Scn} 8 a^{\text {med }}\right.$; stock number 3798; Bar Harbor, ME) and bred them onto the DBA/2J background for three generations. 
The mice were housed under a $12 \mathrm{~h}$ light/dark cycle with ad libitum access to food and water. Unless indicated otherwise, the animals were killed by cervical dislocation at postnatal day 16 (P16). The mice were maintained according to the guidelines of the Canadian Council on Animal Care, and all procedures were approved by the University of Ottawa Animal Care Committee.

Genotyping assay for $\mathrm{Scn} 8 \mathrm{a}^{\mathrm{dmu}}$. The $d m u$ mutation consists of a single nucleotide deletion in exon 10A of the Scn8a coding sequence (position 1538 of GenBank accession number NM_011323). This mutation results in the destruction of a BslI restriction site. A 215 bp fragment of Scn8a containing the mutation is PCR amplified from genomic DNA isolated from tail biopsies using the primers cgggcaccgtctcagaagat (forward) and tccttctcatgccatcttcc (reverse). The PCR product is purified using the MinElute kit (Qiagen, Valencia, CA) and incubated with BslI. Only the wild-type sequences will be digested with $B$ slI.

In situ hybridization. Murine Scn8a digoxigenin (DIG)-labeled "sense" and "antisense" RNA probes were produced. Two different templates were used, one using an NcoI fragment corresponding to position 12332045 of the Scn8a cDNA sequence according to GenBank accession number NM_323011, and another using a PstI-BamHI fragment corresponding to position 2988-3459 of the same sequence. The antisense probe to murine patched was described previously (Jensen and Wallace, 1997). In situ hybridization was performed as described previously by Jensen and Wallace (1997). All probes were used at a 1:1000 dilution in hybridization buffer. After in situ hybridization and incubation with anti-DIG fab fragments (Roche Diagnostics, Indianapolis, IN), specimens were incubated overnight in staining buffer containing nitroblue tetrazolium and 5-bromo-4-chloro-3-indolyl-phosphate (Roche Diagnostics).

Histology and morphometry. Retinas were dissected and placed in fixative (4\% paraformaldehyde in PBS) overnight, incubated in cryoprotectant (30\% sucrose in PBS), frozen in liquid nitrogen-cooled isopentane in a mixture of OCT compound (Sakura, Torrance, CA) and sucrose $(15 \%)$, and sectioned in a cryostat in the plane of the optic nerve. Sections were stained with hematoxylin and eosin, and only sections in which the optic nerve was visible were used for quantification. Using NIH Image software, measurements were taken in wild-type $(n=3)$ and $d m u(n=3)$ retinas at random locations within a distance of $>50 \mu \mathrm{m}$ but $<200 \mu \mathrm{m}$ from the optic nerve stalk by a person unaware of the nature of the samples.

Immunohistochemistry. Eyes were dissected in PBS and processed as follows: after $30 \mathrm{~min}$ of fixation (4\% paraformaldehyde and $0.1 \mathrm{M}$ phosphate buffer, $\mathrm{pH}$ 7.4), the lens was removed through an opening in the anterior chamber, and the eye was fixed for an additional $30 \mathrm{~min}$ and then incubated for $8 \mathrm{~h}$ in a cryoprotective compound ( $30 \%$ sucrose in 0.1 $\mathrm{M}$ phosphate buffer, $\mathrm{pH} 7.4$ ). After a $30 \mathrm{~min}$ incubation at $4^{\circ} \mathrm{C}$ in a matrix (50\% OCT, $15 \%$ sucrose, and $50 \mathrm{~mm}$ phosphate buffer, $\mathrm{pH} 7.4$ ), the eyes were frozen in the matrix with liquid nitrogen-cooled isopentane, sectioned at a thickness of $10 \mu \mathrm{m}$ using a cryostat, dried at room temperature, and stored at $-80^{\circ} \mathrm{C}$. Sciatic nerves isolated from $\mathrm{P} 15 \mathrm{dmu}$ homozygotes and wild-type littermates were processed as described previously (Caldwell et al., 2000). The following primary antibodies were used in this study: mouse monoclonal anti-caspr (contactin-associated protein) (clone 275) (Poliak et al., 1999), "pan-specific" antiserum directed against an epitope present in all vertebrate $\mathrm{Na}_{\mathrm{V}} 1$ isoforms (DugandzijaNovakovic et al., 1995), mouse monoclonal anti-rhodopsin (clone B630) (Rohlich et al., 1989), Chx10 antiserum (gift from Dr. R. Bremner, University of Toronto, Toronto, Ontario, Canada) (Burmeister et al., 1996), CRALBP (cellular retinaldehyde-binding protein) antiserum (gift from J. Saari, University of Washington, Seattle, WA) (De Leeuw et al., 1990), mouse monoclonal HPC-1 against syntaxin 1 (Sigma, St. Louis, MO) (Barnstable et al., 1985), and Brn3b antiserum (Santa Cruz Biotechnology, Santa Cruz, CA) (Xiang et al., 1993); the FITC-labeled lectin peanut agglutinin (Sigma) was used for the detection of cone photoreceptors. For the detection of $\mathrm{Na}_{\mathrm{V}} 1.6$, antibody 848 was used in sciatic nerves (Caldwell et al., 2000). 4',6-Diamidino-2-phenylindole dihydrochloride ( $1 \mu \mathrm{g} / \mathrm{ml}$; Molecular Probes, Eugene, OR) was used on occasion as a chromatin stain. The primary antibodies were detected using cyanine 3 , Alexa 488, Alexa 546, or FITC-conjugated secondary antibodies (Molecular Probes) or a biotinylated secondary antibody (Vector Laboratories,
Burlingame, CA) in conjunction with the ABC Vectastain Elite peroxidase system (Vector Laboratories) in accordance with the instructions of the manufacturer. For imaging of the vasculature, retinas were dissected as whole mounts, flattened, and stained with FITC-labeled Griffonia simplicifolia lectin (Sigma), as described previously (Zhang and Stone, 1997). Photomicrographs were captured using an Axioplan 2 microscope (Zeiss, Thornwood, NY) equipped with an Axiocam digital camera (Zeiss).

Electroretinography. Mice were dark adapted for a minimum of $1 \mathrm{~h}$ before ERG recordings. The animals were anesthetized using avertin (2,2,2-tribromoethanol; $275 \mathrm{mg} / \mathrm{kg}$, i.p.), and a topical analgesic $(0.5 \%$ proparacaine hydrochloride) was applied to the eye before the positioning of the electrode. Body temperature was maintained at $37^{\circ} \mathrm{C}$ using a heated pad, and pupils were dilated using a $1 \%$ tropicamide solution. Both eyes were positioned within the lambertian sphere range of a ColorBurst handheld Ganzfeld stimulator (Diagnosys, Littleton, MA). The reference electrode consisted of a gold-plated connector placed in the mouth. A silver needle was placed subcutaneously in the tail to ground the animal, and the active electrodes placed on the corneas were constructed from Dawson-Trick-Litzkow-plus microconductive fiber (Diagnosys). A 2.5\% hydroxypropyl methylcellulose solution was applied to maintain hydration and to ensure proper conductance. Stimulation and recording were automated using the Espion software suite version 2.37.37 (Diagnosys). Flashes of white light were presented for $4 \mathrm{~ms}$ over a black background at increasing intensities of $-3.0,-2.6,-2.2,-1.8$, $-1.4,-1.0,-0.6,-0.2,0.6,1.0$, and $1.4 \log \mathrm{cd} \cdot \mathrm{s} / \mathrm{m}^{2}$. Between four and six responses were averaged with an interflash interval of $5 \mathrm{~s}$ for stimulus intensities below $-1.0 \log \mathrm{cd} \cdot \mathrm{s} / \mathrm{m}^{2}$ and increased to $10 \mathrm{~s}$ for intensities of $-1.0 \log \mathrm{cd} \cdot \mathrm{s} / \mathrm{m}^{2}$ and above. The marker for the a-wave was placed on the second peak of the trace when more than one peak was apparent, and the marker for the b-wave was placed on the third oscillatory potential. In each animal, the eye that produced the strongest a-wave response at 1.4 $\log \mathrm{cd} \cdot \mathrm{s} / \mathrm{m}^{2}$ was chosen for subsequent analysis. Data were processed using Microsoft (Redmond, WA) Excel.

Electron microscopy. P16 wild-type and homozygous $d m u$ mice were anesthetized by intraperitoneal injection of avertin. The mice were transcardially perfused with $10 \mathrm{ml}$ of PBS followed by $20 \mathrm{ml}$ of Karnovsky's fixative (4\% paraformaldehyde, $2 \%$ glutaraldehyde, and $0.1 \mathrm{M}$ cacodylate in PBS, pH 7.4). The eyes were dissected in PBS, the lens was removed, and the eyes were incubated in Karnovsky's fixative for $4 \mathrm{~h}$. The eyes were hemisected, and "pie slices" were cut around the optic nerve. The samples were washed in cacodylate buffer, treated with $2 \%$ osmium tetroxide, dehydrated, and embedded in Spurr resin (Electron Microscopy Sciences, Hatfield, PA). Sections ( $60 \mathrm{~nm}$ ) were collected onto grids, pretreated with $2 \%$ aqueous uranyl acetate, stained with lead citrate, and observed using a model 1010 transmission electron microscope (Jeol, Peabody, MA).

\section{Results}

\section{$\mathrm{Na}_{\mathrm{V}}$ 1.6-null mice have a strongly reduced sensitivity to light}

We conducted a full-field flash ERG study on two spontaneous mutant alleles of Scn8a. Neither the Scn8a ${ }^{d m u}$ (De Repentigny et al., 2001) (supplemental Fig. 1, available at www.jneurosci.org as supplemental material) nor the $\operatorname{Scn} 8 a^{\text {med }}$ (Burgess et al., 1995) alleles express functional $\mathrm{Na}_{\mathrm{V}}$ 1.6. Various components of the ERG, the retinal field potential elicited by light stimulation, provide information on the activity of distinct cell populations within the retina. In dark-adapted animals, the a-wave, the early negative potential, reflects rod photoreceptor activity (Penn and Hagins, 1969), whereas the later positive b-wave originates from the associated activity of depolarizing (ON) bipolar cells (Stockton and Slaughter, 1989; Green and Kapousta-Bruneau, 1999) and Müller cells (Miller and Dowling, 1970). At P16, the amplitude of the a-wave in $S c n 8 a^{d m u}$ mice is reduced at flash intensities ranging from 0.6 to $1.4 \log \mathrm{cd} \cdot \mathrm{s} / \mathrm{m}^{2}$, and the b-wave is reduced throughout compared with littermate controls (Fig. 1a). Furthermore, the latency times (from flash onset to peak) for both the a- 

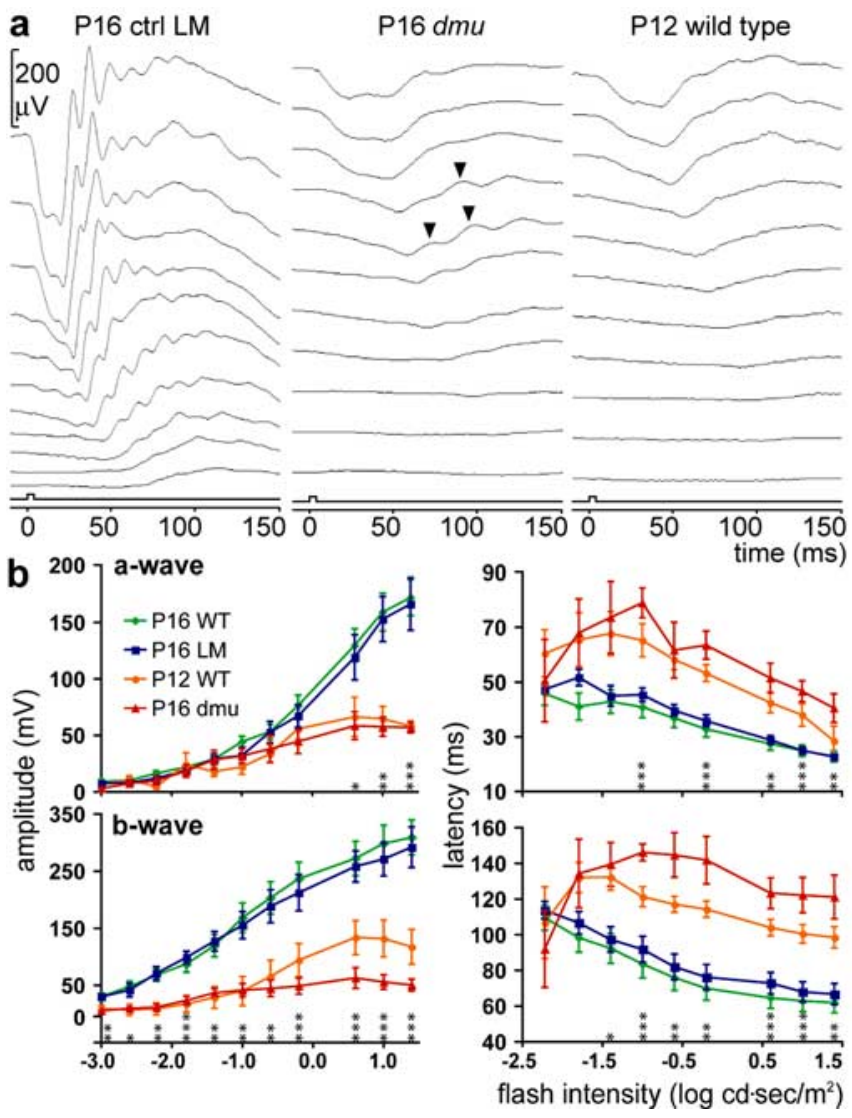

Figure 1. Scn8a-null mice have a strongly reduced sensitivity to light. $\boldsymbol{a}$, Representative ERG response in a P16 control littermate (ctrl LM) of Scn8a ${ }^{d m u}$ mice bred onto the DBA/2J background (left), a P16 Scn8a $a^{d m u}$ homozygous mouse (dmu) bred onto the DBA/2J background (middle), and a P12 wild-type DBA/2J mouse (right). The ERGs were elicited by flashes of white light of increasing intensities ranging from -3.0 (bottom) to 1.4 (top) $\log \mathrm{cd} \cdot \mathrm{s} / \mathrm{m}^{2}$ (square box indicates flash onset and duration). Although ERG components, such as, from left to right, a pronounced a-wave, oscillatory potentials, and a b-wave, can be clearly distinguished in the P16 wild-type mouse, these components are strongly reduced and delayed in Scn8a ${ }^{d m u}$ mice. Oscillatory potentials can occasionally be seen, indicating that synaptic transmission can occur (arrowheads). The amplitude and general appearance of the $S \mathrm{C} n 8 a^{d m u}$ ERG is similar to that of the immature P12 wild-type ERG. $\boldsymbol{b}$, Quantitative analysis of the amplitudes and latencies of the $a$-wave (absolute values) and $b$-wave relative to the flash onset from P16 wild-type DBA/2J mice (P16 WT; $n=18)$, normal littermates of $S \mathrm{c} n 8 a^{d m u}$ mice (P16 LM; $\left.n=6\right)$, P12 wild-type $\mathrm{DBA} / 2 \mathrm{~J}$ mice $(\mathrm{P} 12 \mathrm{WT} ; n=3)$, and P16Scn8a ${ }^{d m u}$ mice (P16dmu; $\left.n=6\right)$. Errorbars represent \pm SEM. P16 Scn8a ${ }^{d m u}$ mice are compared with their littermates using an unpaired Student's $t$ test, and significance is assigned as ${ }^{*} p \leq 0.05,{ }^{* *} p \leq 0.01$, and ${ }^{* * *} p \leq 0.001$.

and $\mathrm{b}$-waves are significantly increased at intensities above -1.0 $\log \mathrm{cd} \cdot \mathrm{s} / \mathrm{m}^{2}$ (Fig. $1 b$ ). Synaptic transmission occurs in the retina of $\operatorname{Scn} 8 a^{d m u}$ mice, because oscillatory potentials can occasionally be observed (Fig. $1 a$ and supplemental Fig. $2 a$, available at www. jneurosci.org as supplemental material), and, after stimulation with bright flashes, $S c n 8 a^{d m u}$ retinas express the intermediate early gene c-fos in bipolar cells and in ganglion cells (data not shown). Similar ERG results were obtained in $\operatorname{Scn} 8 a^{d m u}$ mice bred onto the C57BL/ 6 genetic background and in the Scn8a $a^{\text {med }}$ mice (supplemental Fig. 2a, $b$, available at www.jneurosci.org as supplemental material). Interestingly, however, of 15 Scn8a-null mice tested by ERG, we observed in one instance (an Scn8a $a^{\text {med }}$ mouse) the presence of an a-wave and a b-wave of intermediate amplitude and latency time relative to controls and affected individuals (supplemental Fig. $2 c$, available at www.jneurosci.org as supplemental material), raising the possibility that compensation against the effect of $\mathrm{Na}_{\mathrm{V}} 1.6$ depletion can occur. The ERG re- sponse from P16 Scn $8 a^{d m u}$ mice is very similar to that of P12 wild-type animals (Fig. 1) and suggests that $\mathrm{Na}_{\mathrm{V}} 1.6$ is required during a critical period of retinal development.

\section{Scn8a expression in the retina begins shortly before the time of the observed ERG deficit}

Although no difference was detected between antisense and sense Scn8a probes at stages ranging from P0 (data not shown) to P7 (Fig. 2a), in situ hybridization of retinas isolated at various postnatal time points thereafter produced a signal above background, with the earliest being at P10 (Fig. $2 b$ ). From P10 to P22, staining for Scn8a transcripts was particularly strong in the ganglion cell and inner nuclear layers (Fig. $2 b-f$ ). Comparison of the Scn8a staining with the pattern of patched expression (Fig. $2 g$ ), which is restricted to the narrow band of Müller glia nuclei, indicates that all cell types residing in the inner nuclear layer, including amacrine, bipolar, horizontal, and Müller cells, are candidates for Scn8a expression. Furthermore, it is noteworthy that, in the outer nuclear layer, the staining for $S c n 8 a$ was slightly but consistently above background levels. These results were confirmed using a different probe to $S c n 8 a$ (data not shown) and are consistent with those of Fjell et al. (1997).

\section{The functional deficit does not correlate with morphological abnormalities}

To determine whether the observed electrophysiological deficits were attributable to a developmental defect or to retinal degeneration, we initially compared the retinal morphology of P16 Scn $8 a^{d m u}$ mice with littermate controls. No differences were detected using a number of criteria (Fig. $3 a, b$ ). In addition, ultrastructural analysis indicated that the outer segments of $\operatorname{Scn} 8 a^{d m u}$ photoreceptors have a normal appearance with the presence of ordered stacks of disk membranes (Fig. $3 d$ ). In addition, synaptic ribbons are present at the junction of bipolar and horizontal cell processes within rod spherules, indicating that $S c n 8 a^{d m u}$ photoreceptors form structurally normal synapses with second-order neurons (Fig. 3e,f). Markers for retinal cell types indicated the normal presence of rods, cones, bipolar cells, horizontal cells, amacrine cells, and Müller glia (supplemental Fig. 3, available at www.jneurosci.org as supplemental material).

Null mutants for Scn8a have a reduced lifespan $(\sim 20 \mathrm{~d})$ and at P16 have reduced motility and generalized muscle atrophy (De Repentigny et al., 2001). This raises the possibility that the observed loss of function is caused by a systemic factor (such as hypoxia attributable to labored breathing for example). The retinal vasculature and Müller cells are exquisitely sensitive to oxygen and nutrient deprivation (Stone et al., 1999). Therefore, to address the possibility that the reduced ERG is attributable to an abnormal oxygen or nutrient supply, we stained Müller cells for glial fibrillary acidic protein (GFAP) and the vasculature with a chromophore-conjugated lectin. GFAP staining remained restricted to the end feet of the Müller cells (Fig. 3c), indicating the absence of reactive gliosis. Furthermore, the density and caliber of the capillaries in $S c n 8 a^{d m u}$ retinas were equivalent to those of control animals (supplemental Fig. 4, available at www. jneurosci.org as supplemental material), excluding hypoxia as a causative agent for the retinal defect.

\section{Discussion}

Acute blockade of VGSCs using pharmacological agents has revealed that they are dispensable in the mature retina for the gen- 

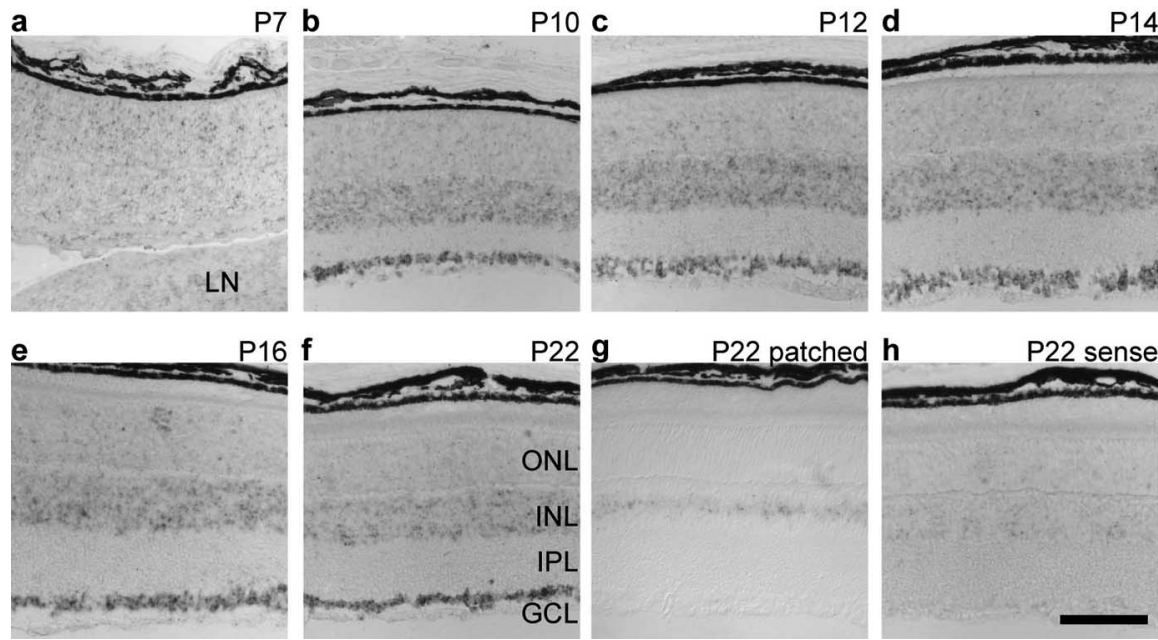

Figure 2. Developmental time course of $S \mathbf{c} 8$ a expression in the retina. $\boldsymbol{a}-\boldsymbol{f}$, In situ hybridization of wild-type retinas during postnatal development with a digoxigenin-labeled Scn8a antisense probe reveals Scn8a expression in the ganglion cell and inner nuclear layers that begins between P7 and P10. The broad expression of Scn8a in the inner nuclear layer is corroborated by comparing with patched $(\boldsymbol{g})$, a marker for Müller cell nuclei, which displays a more restricted expression pattern. $\boldsymbol{h}, \mathrm{Scn} 8$ a sense control. LN, Lens; GCL, ganglion cell layer; IPL, inner plexiform layer; INL, inner nuclear layer; ONL, outer nuclear layer. Scale bar, $100 \mu \mathrm{m}$.
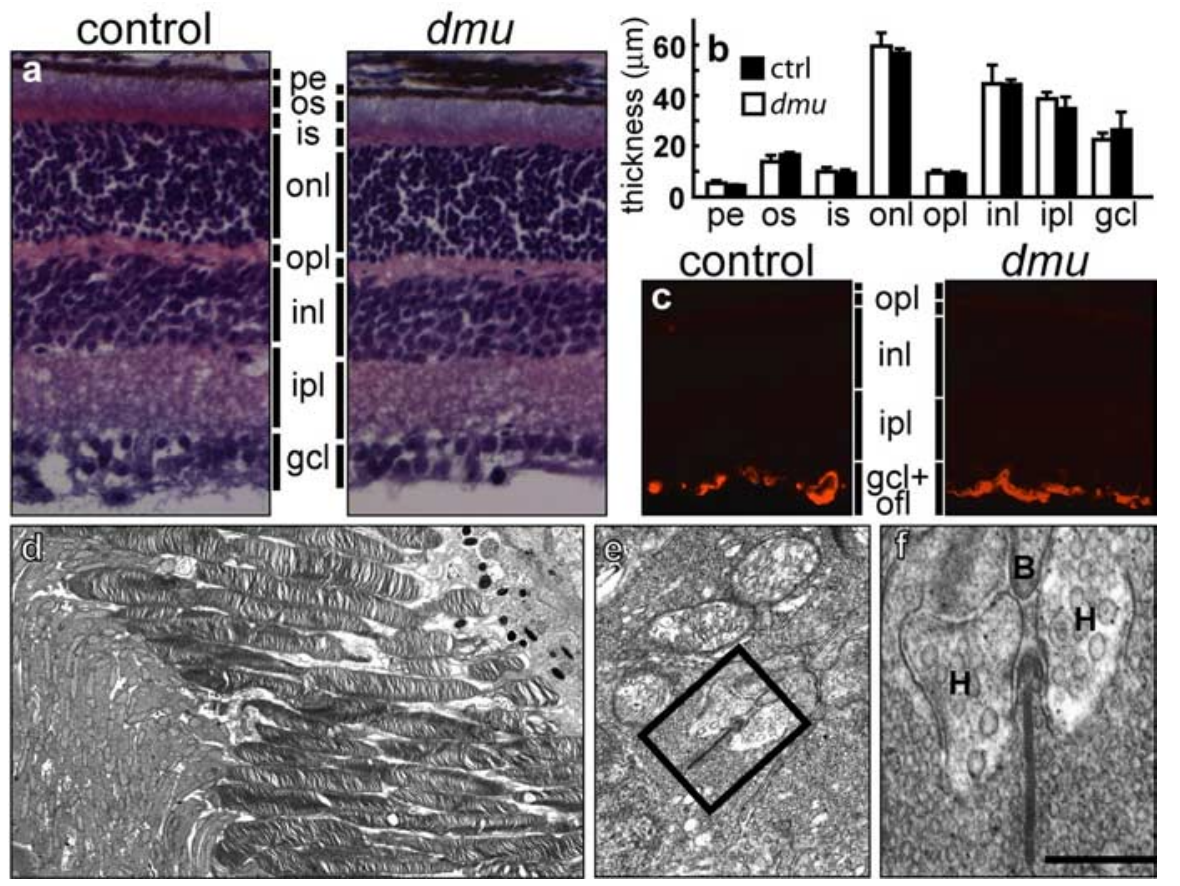

Figure 3. Absence of $\mathrm{Na}_{\mathrm{v}} 1.6$ does not affect retinal morphology. $\boldsymbol{a}$, Hematoxylin and eosin staining of P16 control and P16 $S \mathrm{cn} 8 a^{d m u}(\mathrm{dmu})$ retinas does not reveal overt abnormalities. $\boldsymbol{b}$, Quantification of the layer thickness. Error bars represent SEM. $\boldsymbol{c}$, In $S c n 8 a^{d m u}$ mice, GFAP is restricted to the end feet of Müller cells, indicating the absence of reactive gliosis. $\boldsymbol{d}-\boldsymbol{f}$, A survey of the $S c n 8 a^{d m u}$ photoreceptor ultrastructure at P16 shows normal outer and inner segments with no signs of degeneration (d).e, $\boldsymbol{f}$, In addition, in the outer plexiform layer, bipolar (B) and horizontal $(\mathrm{H})$ dendritic processes invaginate rod spherules to form synaptic clefts that have the normal triad appearance with the electron-dense ribbon located between the horizontal cells. Scale bar: (in f) $\boldsymbol{a}, \boldsymbol{c}, 60 \mu \mathrm{m} ; \boldsymbol{d}, 3 \mu \mathrm{m} ; \boldsymbol{e}, 0.5 \mu \mathrm{m} ; \boldsymbol{f}, 0.2 \mu \mathrm{m}$. pe, Pigment epithelium; 0s, outer segment; is, inner segment; onl, outer nuclear layer; opl, outer plexiform layer; inl, inner nuclear layer; ipl, inner plexiform layer; gcl, ganglion cell layer; ofl, optic fiber layer.
Scn8a-null ERG to the P12 wild-type ERG, favors a developmental function for $\mathrm{Na}_{\mathrm{V}}$ 1.6.

\section{Mode of action of $\mathrm{Na}_{\mathrm{v}} 1.6$ influence on} photoreceptor cell maturation

The function that the $\mathrm{Na}_{\mathrm{V}} 1.6$ sodium channel may have in retinal development is unknown, but its expression in the outer and inner nuclear layers and in ganglion cells in combination with our ERG assessment of Scn8a-null mice suggests the existence of an activity-mediated signaling mechanism necessary for normal photoreceptor maturation.

The observations we made could result from a paracrine effect mediated by neuromodulators or neurotrophins. For example, the absence of $\mathrm{Na}_{\mathrm{V}} 1.6$ may reduce evoked and/or spontaneous activity ( $\mathrm{Ra}$ man et al., 1997; Chen et al., 1999) in retinal ganglion cells, in which this channel is strongly expressed (Fig. 2) (Fjell et al., 1997; Krzemien et al., 2000). In turn, stimulus-induced and spontaneous activity in retinal ganglion cells has been shown to be necessary for the normal expression (Karlsson and Hallbrook, 1998) and trafficking (Chytrova and Johnson, 2004) of brain-derived neurotrophic factor (BDNF), respectively.

A recent study on utricular hair cells, another type of sensory receptor thought to be devoid of VGSCs, has shown that VGSC-mediated activity is responsible for BDNF release from the hair cells but only during the early postnatal period (Chabbert et al., 2003). In turn, BDNF and its specific receptor TrkB (tyrosine receptor kinase B) (Rohrer et al., 1999) are required for the normal maturation of photoreceptors and of the rod pathway. Therefore, the detection of low levels of Scn 8 a expression in the nuclei of photoreceptors in the outer nuclear layer (Fig. $2 b-f$ ) raises another possibility. Activity mediated by $\mathrm{Na}_{\mathrm{V}} 1.6$ may be required in photoreceptors during a restricted period of development for its normal maturation via the action of a neurotrophin, possibly BDNF.

In summary, mice with null mutations in Scn8a produce an abnormal ERG with reduced and delayed components (awave, b-wave, and oscillatory potentials). The absence of obvious morphological abnormalities in the retina leads us to conclude that the physiological defect does not eration of the a-wave (Dong and Hare, 2000; Bui and Fortune, 2003). Furthermore, although action potentials have been reported in mature photoreceptors from human retinal explants (Kawai et al., 2001), the blockade of VGSCs does not affect the photocurrent, and the function of the detected action potentials is unclear. This, in conjunction with the similarity of the P16 result from degeneration, abnormal cell migration, or oxygen or nutrient deprivation. Because previous studies have shown that TTX-sensitive VGSCs, such as $\mathrm{Na}_{\mathrm{V}} 1.6$, are not required for mature photoreceptors to function properly, this work is, to our knowledge, the first demonstration that a VGSC is required in the retina for normal photoreceptor maturation. 


\section{References}

Angaut-Petit D, McArdle JJ, Mallart A, Bournaud R, Pinçon-Raymond M, Rieger F (1982) Electrophysiological and morphological studies of a motor nerve in 'motor endplate disease' of the mouse. Proc R Soc Lond B Biol Sci 215:117-125.

Barnstable CJ, Hofstein R, Akagawa K (1985) A marker of early amacrine cell development in rat retina. Brain Res 352:286-290.

Boiko T, Rasband MN, Levinson SR, Caldwell JH, Mandel G, Trimmer JS, Matthews G (2001) Compact myelin dictates the differential targeting of two sodium channel isoforms in the same axon. Neuron 30:91-104.

Bui B, Fortune B (2003) Ganglion cell contributions to the rat full-field electroretinogram. J Physiol (Lond) 555:153-173.

Burgess DL, Kohrman DC, Galt J, Plummer NW, Jones JM, Spear B, Meisler $\mathrm{MH}$ (1995) Mutation of a new sodium channel gene, Scn8a, in the mouse mutant "motor endplate disease.” Nat Genet 10:461-465.

Burmeister M, Novak J, Liang MY, Basu S, Ploder L, Hawes NL, Vidgen D, Hoover F, Goldman D, Kalnins VI, Roderick TH, Taylor BA, Hankin MH, McInnes RR (1996) Ocular retardation mouse caused by Chx10 homeobox null allele: impaired retinal progenitor proliferation and bipolar cell differentiation. Nat Genet 12:376-384.

Caldwell JH, Schaller KL, Lasher RS, Peles E, Levinson SR (2000) Sodium channel $\mathrm{Na}(\mathrm{v}) 1.6$ is localized at nodes of Ranvier, dendrites, and synapses. Proc Natl Acad Sci USA 97:5616-5620.

Catterall WA (2000) From ionic currents to molecular mechanisms: the structure and function of voltage-gated sodium channels. Neuron 26:13-25.

Chabbert C, Mechaly I, Sieso V, Giraud P, Brugeaud A, Lehouelleur J, Couraud F, Valmier J, Sans A (2003) Voltage-gated $\mathrm{Na}^{+}$channel activation induces both action potentials in utricular hair cells and brainderived neurotrophic factor release in the rat utricle during a restricted period of development. J Physiol (Lond) 553:113-123.

Chen K, Sprunger LK, Meisler MH, Waller HJ, Godfrey DA (1999) Reduced spontaneous activity in the dorsal cochlear nucleus of Scn8a mutant mice. Brain Res 847:85-89.

Chytrova G, Johnson JE (2004) Spontaneous retinal activity modulates BDNF trafficking in the developing chick visual system. Mol Cell Neurosci 25:549-557.

De Leeuw AM, Gaur VP, Saari JC, Milam AH (1990) Immunolocalization of cellular retinol-, retinaldehyde- and retinoic acid-binding proteins in rat retina during pre- and postnatal development. J Neurocytol 19:253-264.

De Repentigny Y, Côté PD, Pool M, Bernier G, Girard S, Vidal SM, Kothary R (2001) Pathological and genetic analysis of the degenerating muscle (dmu) mouse: a new allele of Scn8a. Hum Mol Genet 10:1819-1827.

Dong CJ, Hare WA (2000) Contribution to the kinetics and amplitude of the electroretinogram b-wave by third-order retinal neurons in the rabbit retina. Vision Res 40:579-589.

Duchen LW (1970) Hereditary motor end-plate disease in the mouse: light and electron microscopic studies. J Neurol Neurosurg Psychiatry $33: 238-250$.

Dugandzija-Novakovic S, Koszowski AG, Levinson SR, Shrager P (1995) Clustering of $\mathrm{Na}^{+}$channels and node of Ranvier formation in remyelinating axons. J Neurosci 15:492-503.

Fjell J, Dib-Hajj S, Fried K, Black JA, Waxman SG (1997) Differential ex- pression of sodium channel genes in retinal ganglion cells. Brain Res Mol Brain Res 50:197-204.

Goldin AL, Barchi RL, Caldwell JH, Hofmann F, Howe JR, Hunter JC, Kallen RG, Mandel G, Meisler MH, Netter YB, Noda M, Tamkun MM, Waxman SG, Wood JN, Catterall WA (2000) Nomenclature of voltage-gated sodium channels. Neuron 28:365-368.

Green DG, Kapousta-Bruneau NV (1999) A dissection of the electroretinogram from the isolated rat retina with microelectrodes and drugs. Vis Neurosci 16:727-741.

Jensen AM, Wallace VA (1997) Expression of Sonic hedgehog and its putative role as a precursor cell mitogen in the developing mouse retina. Development 124:363-371.

Karlsson M, Hallbrook F (1998) Kainic acid, tetrodotoxin and light modulate expression of brain-derived neurotrophic factor in developing avian retinal ganglion cells and their tectal target. Neuroscience 83:137-150.

Kawai F, Horiguchi M, Suzuki H, Miyachi E (2001) $\mathrm{Na}^{+}$action potentials in human photoreceptors. Neuron 30:451-458.

Krzemien DM, Schaller KL, Levinson SR, Caldwell JH (2000) Immunolocalization of sodium channel isoform $\mathrm{NaCh} 6$ in the nervous system. J Comp Neurol 420:70-83.

Meisler MH, Kearney J, Escayg A, MacDonald BT, Sprunger LK (2001) Sodium channels and neurological disease: insights from Scn8a mutations in the mouse. The Neuroscientist 7:136-145.

Miller RF, Dowling JE (1970) Intracellular responses of the Muller (glial) cells of mudpuppy retina: their relation to b-wave of the electroretinogram. J Neurophysiol 33:323-341.

Penn RD, Hagins WA (1969) Signal transmission along retinal rods and the origin of the electroretinographic a-wave. Nature 223:201-204.

Poliak S, Gollan L, Martinez R, Custer A, Einheber S, Salzer JL, Trimmer JS, Shrager P, Peles E (1999) Caspr2, a new member of the neurexin superfamily, is localized at the juxtaparanodes of myelinated axons and associates with $\mathrm{K}^{+}$channels. Neuron 24:1037-1047.

Raman IM, Sprunger LK, Meisler MH, Bean BP (1997) Altered subthreshold sodium currents and disrupted firing patterns in Purkinje neurons of Scn8a mutant mice. Neuron 19:881-891.

Rohlich P, Adamus G, McDowell JH, Hargrave PA (1989) Binding pattern of anti-rhodopsin monoclonal antibodies to photoreceptor cells: an immunocytochemical study. Exp Eye Res 49:999-1013.

Rohrer B, Korenbrot JI, LaVail MM, Reichardt LF, Xu B (1999) Role of neurotrophin receptor TrkB in the maturation of rod photoreceptors and establishment of synaptic transmission to the inner retina. J Neurosci 19:8919-8930.

Stockton RA, Slaughter MM (1989) B-wave of the electroretinogram. A reflection of ON bipolar cell activity. J Gen Physiol 93:101-122.

Stone J, Maslim J, Valter-Kocsi K, Mervin K, Bowers F, Chu Y, Barnett N, Provis J, Lewis G, Fisher SK, Bisti S, Gargini C, Cervetto L, Merin S, Peer J (1999) Mechanisms of photoreceptor death and survival in mammalian retina. Prog Retin Eye Res 18:689-735.

Xiang M, Zhou L, Peng YW, Eddy RL, Shows TB, Nathans J (1993) Brn-3b: a POU domain gene expressed in a subset of retinal ganglion cells. Neuron 11:689-701.

Zhang Y, Stone J (1997) Role of astrocytes in the control of developing retinal vessels. Invest Ophthalmol Vis Sci 38:1653-1666. 